Thnen geschildert habe und was Herr Kollege Beythien vorgetragen hat, nur eine Folge dieser schlechten Lage auf dem Lebensmittelmarkte, die augenblicklich herrscht. Unter diesem Gesichtspunkt muß das alles betrachtet werden, and was jetzt augenblicklich geschieht, das kann nicht maḱgebend sein für das, was uns später beschäftigen wird. So war auch mein Schlufiwort gemeint, in dem ich sagte, ich hoffe, dak alles das was wir nun als Zusammenbruch vor uns sehen, gerade für uns Nahrungsmittelchemiker zu einem Erblühen neuen Lebens führen möge.

Prof. Beythien: Ich bin von Herrn Kollegen Behre misverstanden worden. Meine "elegische" Stimmung, die ich zum Ausdruck brachte, entspringt nicht diesem allgemeinen volkswirtschaftlichen Miß́lingen, sondern der Tatsache, daf der Nahrungsmittelchemiker während dieses Krieges zu wenig an den Maknahmen beteiligt war, die erlassen worden sind and die einen auferordentlichen Mangel an Sachkenntnis aufweisen. Ich habe diesen Punkt nicht näher hervorgehoben, weil darüber bei der Besprechung der Ersatzlebensmittelverordnungen näher geredet werden muf. Das waren meine ejgentlichen Beweggründe.

Dr. Le onhard: Ich hatte bei uns in Baden in letzter Zeit auch die Brotkontrolle zu ubernehmen. Kollege Behre hat schon hervorgeboben, daß die Brotkontrolle in ganz falsche Bahnen gelenkt worden ist. Man proft das Brot vielfach nach dem Aussehen und Gewicht. Dabei kommt man zu ganz falschen Ergebnissen. Ein Brot, das zuviel Wasser enthält, wird nicht beanstandet, während ein Brot, das den Vorschriften weitaus mebr entgegenkommt, aber die $1500 \mathrm{~g}$ nicht anfweist, beanstandet wird. Wir habea in Heidelberg die Sache so durchgeführt und zum Teil sehr sehöne Urteile der Strafkammer erzielt. Sie hat regelmüfsig freigesprochen, wenn das Brotgewicht auch nicht erreicht war, wenn nur die Menge Mehl, die dem Bäcker zur Herstellung von $1500 \mathrm{~g}$ Brot zugewiesen war, im Brot enthalten war. Es kommt dem Nahrungsmittelchemiker darauf an, festzustellen, ob das Brot den berechtigten Anforderungen entspricht, und da bin ich der Ansicht, dak wir Nahrungsmittelchemiker uns wehren miissen, das die Kontrolle uber das wichtigste Nahrungsmittel uns entzogen wird. Die Herren machen es gewöhnlich so, daß sie ein Brot durchschneiden, und wenn es naßs aussieht, lassen sio es untersuchen. Nun hat aber die äufere Beschaffenheit mit dem wirklichen Wassergebalt gar nichts zu tun. Ein gutes Brot kann 40-50\% Wasser enthalten und schlecht aussehen. Das ist ein Gebiet, auf dem für die Nahrungsmittelchemiker noch recht viel herauszuholen ist.

Vorsitzender: Das Wort wird nicht mehr gewünscht. Wir können dann diesen Gegenstand verlassen und ich möchte Herm Dr. Grünhut bitten, uns seinen Vortrag über „Nachweis und quantitative Bestimmung der Lävulinsäure in Lebensmitteln" zu halten.

[Der im Nachfolgenden abgedruckte Vortrag lconnte leider wegen der Erkrankung und des inzwischen erfolgten Hinscheidens des Vortragenden von diesem selbst nicht mehr druckfertig abgeschlossen werden. Bei der großen Bedeutung des Gegenstandes erscheint jedoch auch der Abdruck des nicht vollendeten Manuskriptes, das von den Hinterbliebenen zur Verfügung gestellt wurde, an dieser Stelle winschenswert.]

\title{
Nachweis und quantitative Bestimmung der Lävulinsäure in Lebensmitteln.
}

$$
\text { Von }
$$

\section{Grïnhut.}

Mitteilung aus der Deutachen Forschungsanstalt für Lebengmittelchemie in $M \ddot{u} \mathrm{n} e \mathrm{~h} \in \mathrm{n}$.

\section{Vorkommen der Ameisensäure und Lävulinsäure in Lebensmitteln.}

Vor einiger Zeit fand Fr. A dam ${ }^{1}$ ), daß Suppenwürzen, Brühwürfel-Ersatz und sog. Pflanzenfleischextrakte Ameisensäure enthalten. Er bestimmte ihre Menge quantitativ, indem er die mit Schwefelsäure angesäuerte Lösung des zu untersuchenden

1) Archiv f. Chemie u. Mikroskopie 1916, 9, 77. 
Erzeugnisses einer ausgiebigen Destillation im Wasserdampfstrome unterzog, das Destillat in der seit A. Scala ${ }^{1}$ ) bekannten Weise mit Mercurichlorid in Reaktion brachte und schließlich das ausgeschiedene Mercurichlorid wog. So fand er Ameisensäuregehalte zwischen $0,21 \%$ und $2,43 \%$; bezieht man die gefundenen Mengen auf Prozente der fettfreien und kochsalzfreien Trockenmasse, dann entsprechen sie Werten, die zwischen $0,78 \%$ und $6,24 \%$ liegen.

An diese Ergebnisse knüpfte Adam zwei Folgerungen. Einmal wies er darauf hin, daß Ameisensäure als giftig gilt, und daß demnach die Menge begrenzt werden müsse, bis zu der man sie in Suppenwürzen, Brühwürfel-Ersatz und ähnlichen Erzeugnissen dulden könne. Wobl infolgedessen wurde in die zweite Ausgabe der deutsch-österreichischen Richtlinien zur Begutachtung der Ersatz-Lebensmittel vom 2. Dezember 1918 ${ }^{2}$ ) die Bestimmung aufgenommen, daß der Gehalt an Ameisensäure in den fraglichen Erzeugnissen "die amtlich festgesetzte Grenzzahl (derzeit $2 \%$ in der fett- und kochsalzfreien Trockenmasse ${ }^{3}$ )) nicht überschreiten" dürfe. In Deutschland hat man von dem Erlaß einer derartigen Bestimmung abgesehen, vermutlich weil in den letzten Jahren die Anschauungen über die Giftigkeit der Ameisensäure merkliche Einschränkungen erfahren haben ${ }^{4}$ ).

Die zweite Folgerung, die Adam aus seinen Ergebnissen ableitet, betrifft die Herausarbeitung eines Beurteilungsgrundsatzes. Die Würzen und Extrakte, um die es sich hier handelt, werden bekanntlich aus eiweißhaltigen Rohstoffen, vor allem aus technischem Casein und aus Hefe, durch Salzsäurehydrolyse gewonnen. Die eigentlichen Eiweißstoffe liefern aber bei solcher Behandlung keine Ameisensäure; sie entsteht dagegen, wie man schon lange weiß ${ }^{5}$ ), aus den Koblenhydraten beim Erhitzen mit Mineralsäuren. Das Vorkommen von Ameisensäure in Suppenwürzen usw. gestattet somit Rückschlüsse auf das verwendete Ausgangsmaterial und insbesondere auf seinen Kohlenhydratgehalt. Dieser Gesichtspunkt scheint von mancher Stelle einseitig so gedeutet worden zu sein, daß man das Auftreten der Ameisensäure als ein Kennzeichen für die Herstellung des Erzeugnisses aus Milch angesehen hat, denn Fr. Ada $\mathrm{m}^{6}$ ) hielt es nachträglich für nötig, darauf hinzuweisen, dab auch andere Ausgangestoffe kohlenhydratreich sind. Er nennt in diesem Sinne die Leguminosen. In der Tat enthält z. B. die Sojabohne neben $34 \%$ Stickstoffverbindungen $28 \%$ Kohlenhydrate, die Lupine neben $28 \%$ Stickstoffrerbindungen $36 \%$ Kohlenhydrate.

Der Ansicht, daß die Ameisensäure in den Erzeugnissen, von denen bisher hier die Rede war, von der Zerstörung der Kohlenhydrate herrühre, trat auch E. W as er ${ }^{7}$ )

\footnotetext{
1) Chem. Zentralbl. 1890, II, 566.

2) Gedruckt als Flingblatt des Fachkomitees des Deutschösterreichischen Staatsamtes für Volksernährung.

3) Osterreichischer Ministerialerlaß vom 12. Dezember 1917, Z. 8701.

4) Vergl. das Gutachten der Preußischen wissenschaftlichen Deputation für das Medizinalwesen vom 22. März 1911 (Gesetze u. Verordnungen, betr. Nahrungs- u. Genufmitte], 1911, 3, 293),

5) J. W. Döbereiner, Anual. d. Pharmazie 1832, 3, 144. - C. G. Gmelin, Poggendorff's Annalen 1829, 16, 55. - M a la guti, Annal. d. Pharmazie 1836, 17, 59. - G. J. Mulder, Journ. f. praktische Chemie 1840, 21, 206, 208, 219.

6) Taschenbuch f. prakt. Untersuchung der wichtigsten Nahrungs- u. Genulam. 3. Auf. 1919 , s. 115.

7) Zeitschr. f. physiologische Chemie 1917, 99, 67.
} 
bei. Im übrigen wies er jedoch nach, daß Ameisensäure auch im Fleischextrakt vorkommt; die üblichen Handelssorten enthielten 0,06 bis $0,13 \%$; aus frischem Fleisch hergestellte Laboratoriumspräparate hingegen etwa $0,5 \%$. Die Ameisensäure ist nach Waser hier ein Produkt der Autolyse des Muskeleiweißes, d. h. seiner enzymatischen Auflösung beim Aufbewahren unter Wasser. Durch einen Zusatz von Salzsäure zum Wasser, wie er nach Lebbin bei der fabrikmäßigen Herstellung des Fleischextraktes vorgenommen werden soll, wird die Autolyse unterdrückt, deshalb sind die Fabrikerzeugnisse ameisensäureärmer als die im Laboratorium, d. h. ohne Salzsäurezusatz hergestellten.

Stammt die Ameisensäure in den Würzen und den ihnen verwandten Erzeugnissen tatsächlich aus den Kohlenhydraten der Rohstoffe, dann müßte sich notwendigerweise auch die zweite Säure nachweisen lassen, die neben ihr in erheblicher Menge aus Kohlenhydraten bei der Einwirkung von höher konzentrierten Mineralsäuren entsteht, nämlich die Lävulinsäure $\left(\beta\right.$-Acetylpropionsäure, $\left.\mathrm{C}_{5} \mathrm{H}_{8} \mathrm{O}_{3}\right)$. Sie wurde von A. von Grote und B. Tollen s') durch Kochen von Saccharose und von Inulin mit verdünnter Schwefelsäure erbalien; später stellten sie M. Conrad ${ }^{2}$ ) sowie auch A. von Grote, E. Kehrer und B. Tollens ${ }^{3}$ ) aus Saccharose mittels Salzäure dar. Weitere Untersuchungen ergaben, dalo sie auch aus Glykose ${ }^{4}$ ), aus Fructose ${ }^{5}$ ), aus Galaktose ${ }^{6}$ ), aus Lactose ${ }^{7}$ ), aus Raffinose $^{8}$ ), und aus Stärke ${ }^{9}$ ) mittels Mineralsäuren entsteht; Fr. Bente ${ }^{10}$ ) hatte sie überdies aus Filtrierpapier, geschliffenem Tannenholz, Carragheenmoos und linksdrehendem arabischem Gummi erbalten. Nach C. Wehmer und B. Tollens ${ }^{11}$ ) entsteht sie schließlich noch - wie vorauszusehen aus Glykosiden, z. B. aus Saliciu, nach Hedwig Hamburger ${ }^{12}$ ) auch aus Glykosamin, Chitin und Chitose. Wehmer und Tollens haben aus ibren und den sonstigen aufgezählten Ergebnissen den auch heute noch unbestritten gültigen Schluß gezogen, daß die Bildung von Lävulinsäure eine Reaktion aller wahren Hexosegruppen ist.

Die so gewonnenen Kenntnisse wurden von M. Con rad und M. Guthzeit ${ }^{13}$ ) nach der quantitativen Seite weiter ausgebaut. Sie ermittelten die Menge sowohl der bei der Säurespaltung der Kohlenhydrate gebildeten flüchtigen Säure, d. h. der Ameisensäure, als auch der nichtflüchtigen Säure, d. h. der Lä.vulinsäure, auf acidimetrischem Wege. Beide Säuren entstehen in erheblicher Menge; aus 100 Teilen Saccharose z. B. wurden durch 17-stündiges Erhitzen mit 9-10\%-iger Salzsäure 13,8 Teile Ameisensäure und 33,2 Teile Lävulinsäure erhalten. Fast bei allen Kohlenhydraten verhielten sich, wie auch, im eben angefübrten Versuch, die Gewichtsmengen der

1) Liebig's Anualen 1875, 175, 181.

2) Ber. Deutsch. Chem. Gesellsch. 1878, 11, 2178.

3) Liebig's Annalen 1881, 206, 214.

4) A. v. Grote und B. Tollens, Liebig's Annalen 1881, 206, 226.

5) A. v. Grote, E. Kehrer und B. Tollens, Liebig's Annalen 1881, 206, 228.

${ }^{8}$ W. H. Kent und B. 'Iollens, Liebig's Annalen 1885, 227, 227.

7) H. Rodewald und B. Tollens, Liebig's Annalen 1881, 206, 231.

8) P. Rischbieth und B. Tollens, Liebig's Annalen 1886, 232, 193.

9) P. Rischbieth, Ber. Deutsch. Chem. Gesellscb. 1887, 20, 1773.

19) Ber. Deutsch. Chem. Gesellsch. 1875, 8, 416;1876, 9, 1157.

11) Liebig's Annalen 1888, $248,321$.

12) Biochem. Zeitschrift 1911, 36, 1.

39) Ber. Deutsch. Chem. Gesellsch. 1885, 18, 439, 2905; 1886, 19, 2569, 2575. 
beiden Säuren annähernd wie $1: 2,5$, d. h. sie standen im Molekelverhältnis $1: 1$ $(46,02: 116,06=1: 2,52)$. Man darf hieraus schließen, daß die Säurespaltung der Kohlenhydrate - soweit nicht andere zur Abscheidung von Huminstoffen führende Nebenreaktionen dazwisehen treten - nach dem letzthin für Hexosen gültigen Schema erfolgt.

$$
\mathrm{C}_{6} \mathrm{H}_{12} \mathrm{O}_{6}=\mathrm{CH}_{2} \mathrm{O}_{2}+\mathrm{C}_{5} \mathrm{H}_{8} \mathrm{O}_{3}+\mathrm{H}_{2} \mathrm{O}
$$

Der hier skizzierte Bestand unseres Wissens rechtfertigt die vorhin ausgesprochene Erwartung, daß in den Würzen und den mit ihnen verwandten anderen, durch Säureaufspaltung eiweil - und kohlenhydrathaltiger Rohstoffe gewonnenen Erzeugnissen neben der Ameisensäure noch viel größere Mengen an Lävulinsäure vorkommen müssen. In der Tat hat auch schon Adam aus Ohsena.Extrakt und Obsena-Suppenwürfeln, nach Abdestillieren der Ameisensäure, aus dem Destillationsrückstand mittels Ätherperforation eine zweite Säure gewonnen, die mit Phenylhydrazin ein leicht krystallisierendes Hydrazon gab, und deren Zinksalz in seinem Zinkgehalt demjenigen der Lävulinsäure entsprach. Weitere Versuche hat er nicht mehr angestellt, sodaß wir über die Verbreitung unserer Säure nur andeutungsweise, über die quantitativen Mengen, in denen sie auftritt, noch gar nicht unterrichtet sind. Ich habe mir deshalb, als ich im Gefolge anderer Arbeiten an dieses Thema gelangte, die Aufgabe gestellt, zunächst Verfahren zum einfachen qualitativen Nachweis und zur quantitativen Bestimmung der Lävulinsäure in den fraglichen Erzeugnissen auszuarbeiten und sodann mittels ihrer eine Anzahl typischer Produkte zu untersuchen. Über die erzielten Ergebnisse berichte ich nunmebr.

\section{Grundlagen des qualitativen Nachweises und der quantitativen Bestimmung der Lävulinsäure neben Ameisensäure.}

Für die qualitative Prüfung bedurfte es nicht erst der Aufsuchung einer neuen Methode; hier lag vielmehr in einer von A. Kossel und A. Neumann ${ }^{1}$ ) beschriebenen Reaktion eine solche von ausreichender Empfindlichkeit vor, nach der sich, meinen Erfahrungen zufolge, noch $1 \mathrm{mg}$ Lävulinsäure in $0,1 \%$.iger Lösung nachweisen läßrt. Die Reaktion, deren Ausführung im vorliegenden Sonderfalle weiter unten zu besehreiben sein wird, beruht auf der auf Zusatz von Natriumnitroprussid eintretenden Rotfärbung, die sowohl in alkalischer als auch in essigsaurer Lösung beständig ist. Es handelt sich also um eine Übertragung bezw. Ausdehnung von E. Legal's ${ }^{2}$ ) bekannter Acetonprobe auf die als Ketonsäure ja verwandte Lävulinsäure. Eine Verwechslung mit Aceton, die sonach nahe läge, ist jedoch bei der von mir gewählten Ausführungsform ausgeschlossen, denn ich stelle die Prüfung, wie ich weiter unten näher angeben werde, an einem bei alkalischer Reaktion hergestellten Eindampfungsrückstande an, einem Rückstande also, aus dem etwa vorhandenes Aceton oder andere, die Gruppe $-\mathrm{CH}_{2} . \mathrm{CO}$ enthaltende Ketone - die sämtlich gleichfalls die Legal'sche Reaktion geben - durch Abdampfen ausgetrieben sind. Sonach könnte ein positiver Ausfall der Reaktion in meinem Falle außer durch Lävulinsäure höchstens noch durch andere Ketonsäuren mit der Gruppe $-\mathrm{CH}_{2} . \mathrm{CO}$ bedingt sein; ein Vorkommen von solchen ist aber durchaus unwahrscheinlich.

1) Ber. Deutsch. Chem. Gesellsch. 1894, 27, 2220.

2) Jahresbericht über d. Fortschritte d. Tierchemie 1883, 13, 71. 
Eine andere, von L. v. Udráns $\mathrm{zky}^{1}$ ) angegebene Farbenreaktion der Lävulinsäure mit Furolwasser erwies sich für den vorliegenden Zweck als nicht empfindlich genug.

Bei der Suche nach einer geeigneten Methode zur quantitativen Bestimmung der Lävulinsäure erwies sich das Schrifttum als minderergiebig. Ich wenigstens kenne nur eine Arbeit, die sich mit diesem Thema beschäftigt. Sie rührt von B. Savaré ${ }^{2}$ ) her, während Conrad und Guthzeit bei ihrer zuvor erwähnten Untersuchung nur acidimetrische Titrierungen ausgeführt haben. Da Lävulinsäure mit Jodlösung und Kalilauge Jodoform gibt, was übrigens bereits B. Tollens ${ }^{3}$ ) gefunden hatte, so soll sich nach Savaré ibre Menge durch ein maßanalytisches Verfahren ermitteln lassen, welches dem von J. Messinger ${ }^{4}$ ) zur Bestimmung des Acetons angegebenen gleicht, d. h. durch Einwirken titrierter Jodlösung bei alkalischer Reaktion und Zurücktitrieren des Jodüberschusses nach dem Ansäuren. Zur Kritik dieses Vorschlages braucht nur daran erinnert zu werden, wie außerordentlich zahlreich das Heer der Stoffe ist, die unter den gewählten Versuchsbedingungen Jodoform bilden ${ }^{5}$ ). Man erkennt dann, daß Gefahr besteht, andere Stoffe außer Lävulinsäure mitzubestimmen, sobald es sich um die Analyse von Lösungen handelt, deren Zusammensetzung, wie in unserem Falle, von einiger Mannigfaltigkeit ist. Um nur ein Beispiel zu nennen: Die Milchsäure, von deren Vorkommen in Würzen usw. noch zu sprechen sein wird, reagiert mit Jod und Alkali gleichfalls, wenn auch sehr schwach, unter Bildung von Jodoform. Im übrigen haben mich einige orientierende Versuche nicht von einer besonderen Schärfe von Savaré's Verfahren überzeugen können, und so war es aus mehr als einem Grunde für die vorliegende Aufgabe nicht zu verwenden.

Bemüht, ein Verfahren ausfindig zu machen, das eindeutigere Ergebnisse liefert, versuchte ich, ob sich Lävulinsäure nicht durch Oxydation quantitativ in einen anderen analytisch leichter faßbaren Stoff umwandeln lasse. Aus einer Arbeit von B. Tollens ${ }^{6}$, der das Verhalten unserer Säure gegen verschiedene Oxydationsmittel untersuchte, ging hervor, daf bei der Einwirkung von Chromsäure in schwefelsaurer Lösung praktisch als einzige Oxydationsprodukte Essigsäure, Kohlendioxyd und Wasser entsteh€n. Bei Tollens blieb jedoch die Oxydation in quantitativer Beziehung recht unvollständig, sodaß am Ende noch unveränderte Lävulinsäure in der Reaktionsmischung vorhanden war, und ich hatte zu versuchen, ob dem durch Abänderung der Konzentrationsverhältnisse abgeholfen werden könne.

Das gelang in der Tat; es wurden Bedingungen aufgefunden, unter denen die Reaktion praktisch vollständig ist. $50-75 \mathrm{ccm}$ Lösung, in welchen etwa 100 bis $180 \mathrm{mg}$ Lävulinsäure enthalten waren, wurden mit $4 \mathrm{~g}$ Chromtrioxyd $\left(\mathrm{CrO}_{3}\right)$ und $20 \mathrm{ccm}$ verdünnter Schwefelsäure vom spez. Gew. 1,15 2 Stunden am Rückflußkühler zum Kochen erhitzt. Destillierte man hierauf aus der Reaktionsmischung unter ständigem Zufließenlassen von Wasser, sodaß die Raummenge im Kolben möglichst

1) Zeitschr. physiolog. Chemie 1888, 12, 360.

2) Chem. Zentralbl. 1906, II, 1628.

3) Ber. Deutsch. Chem. Gesellsch. 1881, 14, 1950.

4) Ber. Deutsch. Chem. Gesellsch. 1888, 21, 3366.

5) Vergl. die grundlegende Arbeit von A. Lie ben in Liebig's Annalen 1870, Supplementband 7, 218 u. 377.

6) Liebig's Annalen 1881, 206, 257. 
konstant bei $50 \mathrm{ccm}$ erhalten wurde, die entstandene flüchtige Säure ab, so brauchte das Destillat zum Titrieren genau die gleiche Anzahl ccm. ${ }^{1 / 10}$ N.-Kalilauge, die auch zur Neutralisation der angewandten Lävulinsäure erforderlich sind. Auf je 1 Äquivalent Lävulinsäure war also 1 Äquivalent der flüchtigen Säure entstanden. Letztere war unschwer als Essigsäure zu erkennen; einmal durch Ermittelung des Äquivalentgewichtes in der Weise, die A. Juckenack und R. Pasternack ${ }^{1}$ ) gelegentlich der Prüfung der flüchtigen Fettsäuren des Butterfettes heschrieben haben, zum anderen durch den Essigestergeruch, den der Eindampfungsrückstand des neutralisierten Destillates beim Erhitzen mit Schwefelsäure und Alkohol zeigte. Die Reaktion war also sichtlich so, wie es der - freilich nicht ausnahmslos gültigen - Popow.'schen Regel entspricht, d. h. unter Aufspaltung der Lävulinsäuremolekel zwischen CO-gruppe und Propionsäurerest:

gemäß der Gleichung

$$
\frac{\mathrm{CH}_{3} \cdot \mathrm{CO}}{\mathrm{CH}_{2} \cdot \mathrm{CH}_{2}} \cdot \mathrm{COOH}
$$

$$
\mathrm{C}_{5} \mathrm{H}_{8} \mathrm{O}_{3}+7 \mathrm{O}=\mathrm{C}_{2} \mathrm{H}_{4} \mathrm{O}_{2}+3 \mathrm{CO}_{2}+2 \mathrm{H}_{2} \mathrm{O}
$$

vor sich gegangen. Jeder cem $1 / 10 \mathrm{~N}$.-Lauge, der zur Titrierung des Destillates verbraucht wird, entspricht demnach $0,1 \mathrm{Millimol}=11,606 \mathrm{mg}$ Lävulinsäure. Auf diese Weise wurden an acidimetrisch eingestellten Lösungen reiner Lävulinsäure folgende Ergebnisse erhalten:

$\begin{array}{cccc}\text { Lävulinsäure } & & \text { Versuch I } & \text { Versuch II } \\ \text { Angewendet . . . . . . . . } & 110,8 \mathrm{mg} & 166,2 \mathrm{mg} \\ \text { Gefunden. . . . . . . } & 116,5 \% & 175,3 \%\end{array}$

Wenu die gefundenen Werte in beiden Füllen etwas zu hoch ausgefallen sind, so liegt das daran, daß bei diesen ersten Versuchen ein Mitübergehen von Kohlendioxyd mit der Essigsäure noch nicht mit der Sorgfalt ausgeschlossen wurde, die sich auf Grund der bei der Fortsetzung der Arbeiten gemachten Erfahrungen als nötig erwies.

Die geschilderten Versuche hatten zwar einen Weg zur quantitativen Bestimmung der Lävulinsäure gezeigt, befriedigten aber meine Ansprücbe doch noch nicht nach allen Richtungen; Ich war vielmehr bestrebt, das Verfahren so auszugestalten, dab nicht nur die bei der Oxydation gebildete Essigsäure, sondern überdies noch das verbrauchte Chromation ermittelt wird. Gelingt das, so ist es möglich, die Lävulinsäure in einer Operation aus zwei voneinander unabbängigen Messungswerten, also gewissermaßen doppelt, zu bestimmen. Es gäbe das nicht nur eine wünschenswerte Kontrolle, sondern darüber hinaus, sobald beide Werte zu übereinstimmenden Ergebnissen führen, eine sehr willkommene Bestätigung dafür, daß nur Lävulinsäure, und nicht etwa neben ihr noch ein anderer, gleichfalls Essigzäure liefernder Stoff vorlag.

Wollte man diese Absicht verwirklichen, dann war es nötig, statt, wie bei den bisherigen Versuchen, eine nur annähernd abgewogene Menge Chromtrioxyd hinzuzusetzen, der Reaktionsmischung eine genau abgemessene Menge N.-Kaliumdichromatlösung zuzugeben. Man braucht dann bloß nach beendigter Oxydation auf eine bestimmte Raummenge aufzufüllen und kann in einem Teile den Chromatüberschuß

1) Diese Zeitschrift 1904, 7, 203. 
jodometrisch zurückmessen, aus einern anderen Teile aber die gebildete Essigsäure abdestillieren, um schließlich auch deren Menge acidimetrisch zu ermitteln. Da nach der aufgestellten Reaktionsgleichung 1 Millimol Lävulinsäure 7 Atome Sauerstoff bei der Oxydation gebraucht und da andererseits $1 \mathrm{ccm}$ N.Kaliumdichromatlösung (enthaltend $49,03 \mathrm{mg} \mathrm{K}_{2} \mathrm{Cr}_{2} \mathrm{O}_{7}$ ) 1/2 Atom wirksamem Sauerstoff entspricht, so muß 1 Millimol Lävulinsäure $14 \mathrm{ccm}$ der Chromatlösung verbrauchen.

Bei solchen Versuchen kann nicht mit so großem Chromationüberschuß gearbeitet werden, wie bei den bisher beschriebenen, weil man sonst eine unbequem große Menge zurückzutitrieren hätte. Als ich aber die Chromatmenge verringerte, ergab sich die Notwendigkeit, die Schwefelsäurekonzentration der Reaktionsflüssigkeit sehr stark zu erhöhen, da sonst die Oxydation uncollständig bleibt. Das lehren die folgenden Versuche; bei ihnen wurden je $30 \mathrm{ccm}$ Lävulinsäurelösung, mit je $25 \mathrm{ccm}$ N.-Kaliumdichromatlösung (bei Nr. 3 mit $40 \mathrm{ccm}$ ) und mit der in der folgenden Tafel angegebenen Schwefelsäuremenge 2 Stunden (bei Nr. $63 \%$ Stunden) am Rückflußkühler erhitzt; nach dem Erkalten wurde ein Teil der Reaktionsflüssigkeit zurücktitriert. Die Einzelheiten der Versuchsausführung entsprachen der weiter unten folgenden Arbeitsvorschrift. Die nachfolgende Tafel gibt die verbrauchte Menge Kaliumdichromat und das Verbältnis zur angewandten Lävulinsäuremenge an.

Oxydation von Lävulinsänre mit Kaliumdichromat.

(25 ecm N. Kaliumdichromat; 2 Stdn. Kochdauer.)

\begin{tabular}{|c|c|c|c|c|c|c|c|}
\hline \multirow{2}{*}{$\mathrm{Nr}$. } & \multicolumn{2}{|c|}{$\begin{array}{l}30 \mathrm{ccm} \text { Lävulinsäure- } \\
\text { lösung }\end{array}$} & \multicolumn{2}{|c|}{$\begin{array}{l}\text { Der angewandten } \\
\text { Schwefelsäure }\end{array}$} & \multicolumn{2}{|c|}{$\begin{array}{c}\text { Verbrauchtes } \\
\text { Kaliumdichromat }\end{array}$} & \multirow[b]{2}{*}{ Bemerkungen } \\
\hline & $\begin{array}{l}\text { enthal- } \\
\text { tend } \\
\mathrm{mg}\end{array}$ & $\begin{array}{l}\text { entsprechend } \\
\text { Millimol }\end{array}$ & $\begin{array}{l}\text { Raum- } \\
\text { menge } \\
\mathrm{ccm}\end{array}$ & $\begin{array}{l}\text { Konzentra- } \\
\text { tion }\end{array}$ & $\begin{array}{l}\text { insge- } \\
\text { samt } \\
\text { ccm N. }\end{array}$ & $\begin{array}{c}\text { auf 1 Millimol } \\
\mathrm{O}_{5} \mathrm{H}_{8} \mathrm{O}_{3} \\
\text { ccm }\end{array}$ & \\
\hline 1 & 100,2 & 0,863 & 20 & $1+7$ Wasser & 7,07 & 8,19 & - \\
\hline 2 & 100,2 & 0,863 & 20 & $1+3$ & 8,93 & 10,35 & - \\
\hline 3 & 100,2 & 0,863 & 20 & $1+3$ & 8,44 & 9.78 & $40 \mathrm{ccm}$ N.-Dichromat \\
\hline 4 & 100,2 & 0,863 & 20 & $1+1$ & 14,23 & 12,48 & - \\
\hline 5 & 174,3 & 1,502 & 20 & konzentrierte & 19,83 & 13,20 & - \\
\hline 6 & 174,3 & 1,502 & 20 & n & 20,03 & 13,30 & 31/ Stdn. gekocht \\
\hline 7 & 174,3 & 1,502 & 30 & , & 20,96 & 13,95 & - \\
\hline
\end{tabular}

Eine Vermehrung des Kaliumdichromates (Versuch Nr. 3) oder eine Verlängerung der Kochdauer (Versuch Nr. 6) ist also kaum von Einfluß auf das Ergebnis, und erst bei Versuch Nr. 7 wurde der theoretische Verbrauch von $14 \mathrm{ccm}$ N.-Kaliumdichromatlösung und mithin vollständige Oxydation erreicht. Hierbei betrug die Raummenge der Schwefelsäure $35 \%$ von derjenigen der gesamten Reaktionsflüssigkeit; dieses Verhältnis wurde bei allen weiteren in dieser Arbeit mitgeteilten Versuchen eingehalten.

Waren somit die Grundlagen für die quantitative Bestimmung der Lävulinsäure gegeben, so bot nunmehr auch ihre Trennung von der Ámeisensäure, auf die ja im Rabmen der gestellten Aufgabe besonderes Gewicht zu legen war, keine Schwierigkeiten. Ameisensäure läßt sich in einem bescnderen Anteil der zu untersuchenden Lösung leicht in bekannter Weise mittels Mercurichlorid bestimmen, nur muf man beachten, daß sich mit dem Mercurochlorid erhebliche Anteile eines schwer 
löslichen Quecksilbersalzes der Lävulinsäure ausscheiden können. H. Fincke ${ }^{1}$ ) hat bereits gezeigt, daß diese Störung beseitigt wird, wenn man nach Beendigung des Reduktionsversuches Salzsäure zusetzt. Diese löst das lävulinsaure Salz auf, ohne dabei merkliche Mengen Mercurochlorid in Lösung zu nehmen. Meine Erfahrungen bestätigen das; ich habe überdies den Mercurochloridniederschlag immer noch so lange mit salzsäurehaltigem Wasser ausgewaschen, bis Sehwefelwasserstoffwasser im ablaufenden Filtrat kein Mercuroion mehr anzeigte.

Hat man so den Ameisensäuregehalt ermittelt, so unterwirft man einen zweiten Anteil der Lösung in der zuvor beschriebenen Weise der Oxydation mit Kaliumdichromat einschließlich der geschilderten weiteren Behandlung. Ameisensäure wird hierbei glatt zu Kohlendioxyd und Wasser oxydiert ${ }^{2}$ ); auch bei ihrer Gegenwart bleibt folglich die gebildete Essigsäure ein $\mathrm{Maß}$ der ursprünglich vorhandenen Lävulinsäure. Will man überdies deren Menge zur Kontrolle aus dem Dichromatverbrauch ableiten, so muß man natürlich, gemäß der Reaktionsgleichung

$$
\mathrm{CH}_{2} \mathrm{O}_{2}+\mathrm{O}=\mathrm{CO}_{2}+\mathrm{H}_{2} \mathrm{O} \text {, }
$$

zuvor für jedes Millimol gefundener Ameisensäure $2 \mathrm{ccm} \mathrm{N}$.-Kaliumdichromatlösung in Abzug bringen. Von dem Rest entsprechen dann wiederum je $14 \mathrm{ccm} 1 \mathrm{Millimol}$ Lävulinsäure. Derart angestellte Analysen selbstbereiteter Mischungen von Ameisensäure und Lävulinsäure führten zu sehr befriedigenden Ergebnissen.

Auf die Analyse der Würzen und verwandten Erzeugnisse läßt sich das so herausgearbeitete Verfahren aber nicht unmittelbar anwenden, weil sie natürlich noch andere, durch Chromation oxydierbare Stoffe enthalten als die beiden in Rede stehenden Säuren. Diese müssen deshalb zuvor isoliert werden. Auf dem Wege der Destillation kann das nicht geschehen, denn die Lävulinsäure ist, wie schon Berthelot und Andrés fanden und wie ich bestätigte, mit Wasserdämpfen zwar nicht unflüchtig, aber doch recht schwer flüchtig. Dazu kommt, daß bei einer Destillation aus angesäuerter Lösung eine Neubildung von Ameisensäure und Lävulinsäure aus etwa im Untersuchungsobjekt vorhandenen Kohlenhydraten und damit eine Verschiebung der ursprünglichen Zusammensetzung Platz greifen kann. So war denn ein anderer Weg zu beschreiten, der durch die verhältnismäßig leichte Löslichkeit der beiden Säuren in Äther gewiesen war: die Perforation mit Äther aus angesäuerter Lösung.

Für die Perforation hat sich mir der Apparat von C. von der Heided) auch bei dieser Gelegenbeit als besonders geeignet erwiesen. Zum Ansäuern der Lösung benutzte ich Phosphorsäure; würde man statt ihrer Schwefelsäure nehmen, so bestünde Gefahr, die Wasserstoffionenkonzentration derart zu steigern, daß aus dem immer sehr kochsalzreichen Untersuchungsobjekt Salzsäure in das Ätherperforat übergeht, die bei der Oxydation mit Chromation störend wirken müßte. Daß das beim Ansäuern mit Phosphorsäure nicht eintritt, davon habe ich mich durch besondere Versuche überzeugt.

1) Diese Zeitschrift 1911, 22, 96 .

$\left.{ }^{2}\right)$ D. S. Macnair, Chemical News 1887, 55, 229. - Vergl. auch F. Schwarz und O. Weber, Diese Zeitschrift 1909, 17, 194. - Fr. Freyer, Chem.Ztg. 1895, 19, 1184.

$\left.{ }^{3}\right)$ Ann. chim. phys. 1897, [7] 11, 66.

4) Diese Zeitschrift 19C9, 17, 317. 
Noch ein zweites ist bei der Perforation zu beachten. Perforiert man mit Phosphorsäure angesäuerte Ameisensäurelösung - das gleiche gilt übrigens auch für mit Schwefelsäure versetzte - so gelingt es auch bei sehr langer Perforationsdauer nicht, die Lösung völlig zu erschöpfen. Nachstehende Versuche geben den Beleg hierfür:

Perforation von Ameisensäurelösungen mit Äther.

\begin{tabular}{l|c|c|c|c}
\hline & $\begin{array}{c}\text { Ameisensäure } \\
\text { in der perforierten } \\
\text { Lösung }\end{array}$ & $\begin{array}{c}\text { Perforations } \\
\text { daner }\end{array}$ & $\begin{array}{c}\text { Im Perforat gefundene } \\
\text { Ameisensäure }\end{array}$ \\
\cline { 4 - 5 } & $\mathbf{m g}$ & Stunden & $\mathrm{mg}$ & $\begin{array}{l}\text { Prozente der } \\
\text { angewandten }\end{array}$ \\
\hline $\mathbf{1}$ & 93,6 & 3 & 72,2 & 77,1 \\
$\mathbf{2}$ & 93,6 & 3 & 79,0 & 84,4 \\
$\mathbf{3}$ & 93,6 & 5 & 73,0 & 78,0 \\
$\mathbf{5}$ & 46,8 & 3 & 33,2 & 70,9 \\
5 & 93,6 & 10 & 73,2 & 78,2
\end{tabular}

Die Minderbefunde finden ihre Erklärung in der hohen Dampfspannung der Ameisensäure in ätherischer Lösung, kraft deren Anteile von ihr mit den Ätherdämpfen aus dem Kölbchen immer wieder in den Perforationsraum des Apparates hinaufdestillierten. Abhilfe ist leicht zu schaffen, wenn man in das Kölbchen etwas La uge bringt, welche die Ameisensäure bindet. Dann ist, wie meine Versuche lehrten, wenigstens für die hier in Betracht kommenden Mengen, in drei Stunden sowohl für Ameisensäure als auch für Lävulinsäure eine praktisch vollständige Per. foration zu erreichen. Die gleichen Beobachtungen baben übrigens auch H. D. Dakin, N. W. Janney und A. W. Wakeman ${ }^{1}$ ), ferner O. Riesser ${ }^{2}$ ) sowie J. Pinnow ${ }^{3}$ ) bei der Perforation von Ameisensäurelösungen gemacht, und sie haben auch zu einem analogen Abhilfsmittel gegriffen.

Nach beendigter Perforation bringt man den Inhalt des Kölbchens in einen Scheidetrichter, trennt die wässerige Phase von der ätherischen ab und wäscht letztere mehrmals mit alkalischem Wasser nach. Die vereinigten alkalischen Flüssigkeiten dampft man zur Entfernung des darin gelösten Äthers zur Trockne, nimmt den Rückstand mit Wasser auf und verwendet aliquote Teile der erhalienen Lösung zu den drei erforderlichen Untersuchungen, d. h. zur qualitativen Prüfung auf Lävulin. säure, zur quantitativen Bestimmung der Ameisensäure und zur Ausführung des Oxydationsversuches mit Kaliumdichromat. Auf die Entfernung des gelösten Äthers ist besonderes Gewicht zu legen. Die anfängliche Nichtbeachtung dieser Notwendigkeit führte bei meinen ersten Versuehen zu gänzlich unbrauchbaren Ergebnissen; erst nachdem ich meinerseits als Ursache des Fehlschlagens erkannt hatte, daß Äther durch Chromation zu Essigsäure oxydiert wird, fand ich, daß diese Reaktion des Äthers bereits Grabowsky ${ }^{4}$ ) bekannt gewesen war.

1) Journal of biological ehemistry $1913,14,241$.

2) Zisitschr. physiolog. Chemie 1915/16, 96, 360 .

$\left.{ }^{3}\right)$ Diese Zeitschrift 1919, 37, 62

$\left.{ }^{4}\right)$ Ber. Deutsch. Chem. Gesellsch. 1870, 3, 988. 


\section{Berïeksichtigung von Essigsäure und Milchsäure.}

Mit den vorstehend mitgeteilten Versuchen schien das gesuchte Analysenverfahren auf hinreichend sichere Grundlage gestellt zu sein, und ich ging dazu über, mittels desselben eine Anzahl aus dem freien Verkehr entnommener Erzeugnisse zu untersuchen. Dabei bot sich alsbald ein unerwartetes Ergebnis. Von den analysierten Proben zeigten nämlich bei der Chromatoxydation nur zwei innerhalb der zulässigen Feblergrenzen das nach S. 267 zu erwartende Verbältnis 14:1 zwischen Chromatverbrauch (abzüglich des der Ameisensäure entsprechenden Betrages) und Essigsäure. Bei „Hawil“ betrug jenes Verhältnis 13,9:1, bei "Cenovis-Suppenwürze" 13,8:1. In allen anderen Fällen wurden weit niedrigere Verhältnisse beobachtet, bis herab zu 3,2:1 bei „Dr. Eichloff's Fleischersatz"; aber auch bei diesen Erzeugnissen war nach der Oxydation praktisch keine andere Säure nachzuweisen als Essigsäure.

Die Herabsetzung des Verhältnisses konnte zwei Ursachen haben: Entweder war der Chromatverbrauch verringert oder die Essigsäuremenge erhöht. Demnach war sowohl mit der Gegenwart eines Stoffes zu- rechnen, der zur Oxydation weniger Chromation verbraucht als Lärulinsäure, als auch damit, daß Essigsäure schon von Haus aus ein Bestandteil der betreffenden Proben war und sich - da sie ja durch Chromat nicht weiter oxydiert wird - in ibrem vollen Betrage zu der unter der Einwirkung des Chromats erst aus anderen Stoffen entstehenden hinzugesellt.

Hält man in Beziehung auf die erste dieser beiden Möglichkeiten im Kreise der Stoffe Umschau, deren Vorkommen bei einem Lebensmittel vermutet werden darf, so sind Aminosäuren, an die man bei unseren Objekten begreiflicherweise zuerst denkt, wegen ihrer Schwerlöslichkeit in Äther auszuschließen ${ }^{1}$ ), und die Gedanken bleiben alsbald bei der Milchsäure haften. Wir wissen von ihr ${ }^{2}$ ), daß sie durch Chromsäuregemisch zu Essigsäure, Kohlendioxyd und Wasser oxydiert wird, und P. Szeberén $\mathrm{yi}^{3}$ ) hat dieses Verhalten bereits zu quantitativen Ermittelungen herangezogen. Die Umsetzung verläuft gemäß乃 der Gleichung

$$
\mathrm{C}_{3} \mathrm{H}_{6} \mathrm{O}_{3}+2 \mathrm{O}=\mathrm{C}_{2} \mathrm{H}_{4} \mathrm{O}_{2}+\mathrm{CO}_{2}+\mathrm{H}_{2} \mathrm{O}
$$

und auf 1 Millimol gebildeter Essigsäure werden demnach nur 2 Millimol Sauerstoff, entsprechend $4 \mathrm{ccm}$ N.-Kaliumdichromatlösung verbraucht. Eine Beimischung von Milcbsäure zu Lävulinsäure würde also tatsächlich eine wesentliche Herabsetzung des Chromat-Essigsäure-Verhältnisses zur. Folge haben. Überdies läßt sie sich ihren wässerigen Lösungen durch Perforation mit Äther entziehen und sie bleibt zurück, wenn man das Perforat bei alkalischer Reaktion eindampft; sie muß sich demnach bei der Analyse der Würzen usw. im zuvor entworfenen Rahmen an derselben Stelle finden wie die Lävulinsäure und die Ameisensäure. Das gleiche gilt auch für Essigsäure.

Hatte ich mir anfangs nur die Aufgabe gestellt, ein Verfahren zur analytischen Bestimmung und Trennung von Ameisensäure und Lävulinsäure auszuarbeiten, so

1) In einem besonderen Versuch habe ich mich überdies davon überzeugt, daf in dem Ätherperforat von Suppenwärze kein formoltitrierbarer Stickstoff zugegen ist.

2) L. Dossios, Zeitschr. f. Chemie 1866,9,451. - E. T. Chapman und M. H. Smith, Ebendaselbst 1867, 10,308.

3) Zeitschr. analyt. Ohemie 1917, 56, 505. - Vergl auch O. Schuppli, Chem. Zentralbl. $1919, \mathrm{II}, 894$. 
nötigten nunmehr die vorgeführten Erwägungen zu einer Erweiterung des Problems und zu dessen Ausdehnung auf Essigsäure und Milchsäure. Dafür war es nötig, zunächst das Verhalten der Milchsäure gegen Chromation - die Unangreifbarkeit der Essigsäure stand ja schon von vornherein fest - unter den Versuchsbedingungen zu prüfen, die ich für die vollständige Oxydation der Lävulinsäure als notwendig erkannt hatte, und dabei ergab sich, dab bei der erforderlichen hohen Schwefelsäurekonzentration leicht etwas Chromat zu viel verbraucht und eine entsprechende Menge Essigsäure zu wenig gefunden wird. Es war also, wie das auch Szeberényi unter seinen Versuchsbedingungen beobachtet hatte, die Oxydation sichtlich zu einem kleinen Teil in andere Bahnen gelenkt und, vermutlich über Oxalsäure als Zwischenstufe, zu

$$
\mathrm{C}_{3} \mathrm{H}_{6} \mathrm{O}_{3}+6 \mathrm{O}=3 \mathrm{CO}_{2}+3 \mathrm{H}_{2} \mathrm{O}
$$

fortgeschnitten. Eine Herabsetzung der Schwefelsäurekonzentration drängt diese Nebenreaktion soweit zurück, daß sie praktisch bedeutungslos bleibt; der Versuch ist deshalb bei gleichzeitiger Gegenwart von Milchsäure und Lävulinsäure derart auszu-

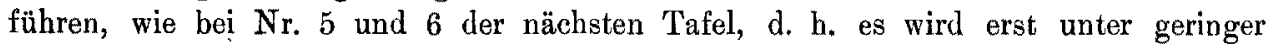
Schwefelsäuregabe die Oxydation der ersteren ảurchgeführt und danach unter vermehrter Säuregabe auch diejenige der zweiten vollendet. Einige Belege über das Verhalten der Milchsäure gibt die folgende Tafel.

Oxydation der Milchsüure mittels Chromations.

\begin{tabular}{|c|c|c|c|c|}
\hline \multirow[b]{2}{*}{$\mathrm{Nr}$. } & \multirow[b]{2}{*}{ Versuchsausführung } & \multirow{2}{*}{$\begin{array}{c}\text { Angewandte } \\
\text { Milchsäure } \\
\mathrm{mg}\end{array}$} & \multicolumn{2}{|c|}{ Gefundene Milchsäure } \\
\hline & & & $\begin{array}{l}\text { Aus Chromat- } \\
\text { verbrauch (Ver- } \\
\text { lä̈ltuis } 4: 1 \text { ) } \\
\text { mg }\end{array}$ & $\begin{array}{l}\text { Aus der } \\
\text { flüchtigen } \\
\text { Säure } \\
\text { mg }\end{array}$ \\
\hline 1 & $\left|\begin{array}{l}20 \mathrm{ccm} \text { Milchsäurelösung wurden mit } 4 \mathrm{~g} \\
\text { Chromtrioxyd }\left(\mathrm{CrO}_{3}\right) \text { und } 20 \mathrm{cem} \text { verd. }\end{array}\right|$ & 182,7 & - & 177,3 \\
\hline 2 & $\begin{array}{c}\text { Schwefelsäure (1,15) } 2 \text { Stunden am Rück- } \\
\text { fluß̧kühler gekocht }\end{array}$ & 182,7 & - & 183,4 \\
\hline $\mathbf{3}$ & $\left|\begin{array}{l}40 \mathrm{ccm} \text { Milebsäurelösung, } 25 \mathrm{ccm} \text { N.-Kalium- } \\
\text { dichromatlösung und } 5 \mathrm{ccm} \text { konc. Schwefel. }\end{array}\right|$ & 216,8 & 218,4 & 211,2 \\
\hline 4 & $\begin{array}{c}\text { säure } 2 \text { Stunden am Rückflaßkühler ge- } \\
\text { kocht }\end{array}$ & 433,5 & 427,6 & - \\
\hline 5 & $\begin{array}{l}40 \mathrm{ccm} \text { Milchsäurelösung, } 25 \mathrm{ccm} \text { N.-Kalium- } \\
\text { dichromatlösung und } 5 \mathrm{ccm} \text { kone. Schwefel- }\end{array}$ & 216,8 & 225,8 & 224,9 \\
\hline 6 & $\begin{array}{c}\text { kocht, dann } 30 \text { ecm kone. Schwefelsänre } \\
\text { zugegeben und } 2 \text { Stunden weitergekocht }\end{array}$ & 438,5 & 443,8 & 421,4 \\
\hline
\end{tabular}

Nachdem somit die geeigneten Bedingungen für die Versuchsausführung festgelegt waren, blieb zu erwägen, wie bei gleichzeitiger Gegenwart der vier Säuren diese, etwa unter Heranziehung der indirekten Analyse, getrennt werden können. Dazu lassen sich folgende Betrachtungen anstellen:

Die Menge der in der Einwage vorhandenen Ameisensäure, Essigsäure, Milchsäure und Lävulinsäure, a usgedrückt in Millimol (= ccm N.-Lösung) sei entsprechend den Anfangsbuchstaben - mit a, e, $m$ und 1 bezeichnet. Hat man bei der Ameisensäurebestimmung (nach Umrechnung auf die gesamte Einwage) A Millimol 
Mercurochlorid (dessen Formel $=\mathrm{HgCl}$, entsprechend einem Molekelgewicht von 236,1 angenommen ist) gefunden, so gilt die Beziehung

$$
\mathrm{a}=0,5 \mathrm{~A} \text {. }
$$

Betrug ferner der Verbrauch der Gesamteinwage an N.-Kaliumdichromatlösung $\mathrm{C}$ ccm, so ergibt sich aus den - bereits mitgeteilten - Reaktionsgleichungen für die drei Säuren als zweite Beziehung

$$
2 \mathrm{a}+4 \mathrm{~m}+14 \mathrm{l}=\mathrm{C} \text {. }
$$

Bezeichnet man endlich die Menge der nach der Oxydation vorhandenen Essigsäure, gleichfalls bezogen auf die Gesamteinwage und ausgedrückt in Millimol, mit E, so besteht als dritte Beziehung

$$
\mathrm{e}+\mathrm{m}+\mathrm{l}=\mathrm{E} \text {. }
$$

Zur Aufsuchung von vier Unbekannten bedarf man aber vier Grundgleichungen. Um die noch fehlende vierte Gleichung gewinnen zu können, erscheint auf den ersten Blick der Gedanke fruchtbar, den drei ausgeführten Bestimmungen als vierte die Ermittelung der Gesamtacidität des Ätherperforates anzugliedern. Verbraucht man zu dessen Titrierung $\mathrm{G}$ cem N.-Lauge, so gilt

$$
a+e+m+1=G \text {. }
$$

Leider führt das nicht zum Ziel. Durch Vereinigung von Gleichung (1) mit Gleichung (3) gelangt man nämlich gleichfalls zu einem Wert für die in (4) enthaltenen Säuren, indem sich ergibt

$$
\mathrm{a}+\mathrm{e}+\mathrm{m}+\mathrm{l}=0,5 \mathrm{~A}+\mathbf{E} .
$$

Die vier Gleichungen sind also nicht voneinander unabbängig und gestatten deshalb nicht die Lösung der gestellten Aufgabe. Dazu kommt als praktische Erschwerung, daß eine hinreichend genaue Ermittelung von $G$ kaum durchführbar ist. Die im Perforationskölbchen vorgelegte N.-Lauge nimmt nämlich, außer den vier zu bestimmenden Säuren, während der mehrstündigen Perforationsdauer noch reichlich Kohlendioxyd aus der Luft auf, sodaß bei dem nachfolgenden Zurücktitrieren, wobei als Endanzeiger Phenolphthalein genommen werden muß ${ }^{1}$ ), G merklich zu hoch gefunden wird.

Erwies sich somit, trotz der Aufstellung der vierten Gleichung, die Trennung von vier Säuren als undurchführbar, so zeigte sich sogleich ein anderer Weg. Gelingt es nämlich, durch eine Vorbehandlung die Lösung in zwei Anteile zu scheiden, deren jeder nicht mehr als drei von den betreffenden Säuren enthält, so ließen sich diese, in jedem Anteil für sich, auf Grund von drei Gleichungen gesondert ermitteln. Zu solcher Vorbehandlung erschien die Destillation als geeignetes Verfahren.

Destilliert man eine Lösung der vier. Säuren, so war zunächst die Annahme berechtigt, daf das Destillat praktisch keine Milchsäure, wohl aber die gesamte Essigsäure, die überwiegende Hauptmenge der Ameisensäure und einen kleinen Anteil der mit Wasserdämpfen ja nur schwer flüchtigen Lävulinsäure enthalten würde. Im Destillationsrückstand hingegen würde keine Essigsäure, dagegen in der Regel ein kleiner Rest der Ameisensäure ${ }^{2}$ ), ferner die Gesamt-Milchsäure und der Hauptanteil der Lävulinsäure zu erwarten sein. Führt man sowohl im Destillat als auch im Rückstand je die Ameisensäurebestimmung und die Chromatoxydation einschließlich

t) Methylorange ist wegen der Essigsänre unzulässig.

${ }^{2}$ ) H. Fincke (Diese Zeitschrift 1911, 21, 7; 22, 90) und andere zeigten, wie schwer die letzten Anteile der Ameisensäure übergehen. 
der Ermittelung der dann vorhandenen Essigsäure durch, so lassen sich jedesmal auf die zusammengehörigen drei Ergebnisse die drei Gleichungen (1), (2) und (3) anwenden, sobald man für das ja praktisch milchsäurefreie Destillat $\mathrm{m}=0$, für den keine Essigsäure mehr enthaltenden Rückstand $\mathrm{e}=0$ setzt. Es sind also lediglich zweimal drei Gleichungen mit je drei Unbekannten aufzulösen und die zusammengehörigen Werte für a und für I im Destillat und Rückstand zu addieren.

Der vorgezeichnete Weg kann natürlich nur dann beschritten werden, wenn tatsächlich die Milchsäure mit Wasserdämpfen praktisch nicht übergeht. So spielt die viel erörterte und öfter umstrittene Frage nach der Flüchtigkeit der Milchsäure in unsere Aufgabe hinein, und ihre grundsätzliche Bedeutung sowie einige sonderbare Wabrnehmungen, die ich bei meinen ersten Analysen machte, veranlaßten mich, sie einer erneuten experimentellen Prüfung zu unterziehen.

\section{Die Flüchtigkeit der Milchsäure mit Wasserdämpfen.}

Selbstverständlich handelt es sich hier nicht um die Flüchtigkeit der Milchsäure als reiner Stoff, für die ja F. Krafft und W. A. Dyes ${ }^{1}$ ) sicher erwiesen haben, $\mathrm{da} B$ sie im hohen Vakuum leicht überzugehen vermag. Die Frage, die hier interessiert, ist vielmehr diejenige nach der Flüchtigkeit der Milchsäure bei Atmosphärendruck aus ihrer wässerigen Lösung, d. h. nach ihrer Fähigkeit mit Wasserdampf überzudestillieren. In diesem Sinne hat sie von Alters her als so schwer flüchtig gegolten, daß bei den gewöbnlichen analytischen Ermittelungen der etwa überdestillierende Anteil in der Regel praktisch vernachlässigt werden kann. Das ist insbesondere auch durch die Untersuchungen von J. A. M üller ${ }^{2}$ ) bestätigt worden. Dieser bestimmte an einer $5 \%$ igen Milchsäurelösung die physikalisch-chemische Gesetzmäßigkeit, welche die hier in Rede stehende Erscheinung regelt, und vermochte sie durch eine Formel auszudrücken, die, in einer von mir daran vorgenommenen Modifikation, folgende Gestalt besitzt:

$$
\log (1-0,01 x)=0,0053 \log (1-0,01 a)
$$

Hierin bedeutet $\mathbf{x}$ den beim Destillieren übergehenden Anteil der Milchsäure, ausgedrückt in Prozenten der ursprünglich in der Lösung vorbandenen Gesamtmenge, und a den prozentischen Anteil der Lösung, der abdestilliert worden ist. Destilliert man also von 100 Raumteilen einer $5 \%$-igen wässerigen Milchsäurelösung 95 Raumteile über $(a=95)$, so wird $x=1,6 ; d$. h. nur $1,6 \%$ der vorhandenen Milchsäuremenge destillieren über und $98,4 \%$ bleiben unflüchtig zurück.

Die Anschauung, daß die Flüchtigkeit der Milchsäure mit Wasserdämpfen praktisch unbeachtlich sei, wurde erst durch A. Partheil ${ }^{3}$ ) erschüttert, der gefunden zu haben glaubte, daß Milchsäure mit Wasserdampf von normaler Spannung recht merklich und mit überhitztem Wasserdampf aus konzentrierten Lösungen sogar vollständig flüchtig ist. Selbst unter den Versuchsbedingungen, unter denen bei der Weinanalyse die flüchtige Säure übergetrieben zu werden pflegt, sollen nach Partheil erhebliche Mengen Milchsäure mit übergehen, die dann im Destillate in der Hauptsache als sog. "gebundene" Milchsäure, d. h. in anhydrisiertem Zustande, vorhanden sind.

1) Ber. Dentsch. Chem. Gesellsch. 1895, 28, 2589.

2) Bull. de la Soc. chim. de Paris 1896, [3] 15, 1206.

3) Diese Zeitschrift 1902, 5, 1053.

N. 21. 
Diesen Behauptungen Partheil's') ist damals sofort von den verschiedensten Seiten - teilweise in privaten Kreisen, zum anderen Teile in Veröffentlichungen entgegengetreten worden. Von letzteren erwähne ich, daß nach J. M a yrhofer ${ }^{2}$ ) im Höchstfall 2,7\% der gesamten Milchsäure ins Destillat gehen. Ferner erhielt R. Kunz ${ }^{3}$;, als er aus $500 \mathrm{~cm}$ Milchsäurelösung unter Einengen auf die Hälfte im Wasserdampfstrome 1 Liter abdestillierte, gleichfalls nur 3,5\% der Milchsäure im Destillat. F. Utz ${ }^{4}$ ) destillierte 5,4\% $\%$ ige Milchsäurelösung im Wasserdampfstrome eine halbe bezw. eine Stunde; im Destillat wurden $0,5 \%$ bezw. $0,7 \%$ der angewandten Menge gefunden, und nur bei Anwendung stark konzentrierter Lösung war eine größere Flüchtigkeit zu beobachten. In denselben Grenzen, teilweise sogar noch niedriger, liegen die Werte, welche E. B. Hart und J. J. Willaman ${ }^{5}$ ). fanden. Sie batten bei ihren Versuchen besonderen Wert darauf gelegt, dah das Wasser im Dampfentwickler, das den strömenden Dampf für die Destillation lieferte, praktiseh frei von Koblendioxyd war, und sie vermochten überzeugend darzutun, daß die scheinbar größere Flüchtigkeit der Milchsäure, welche A. W. Dox und R. E. Neidig ${ }^{6}$ ) wahrgenommen haben wollten, auf die Unterlassung dieser Vorsichtsmaßregel zurückzufübren ist. Dox und Neidig hatten eben in ihren Destillaten Kohlensäure titriert und diese für Milchsäure gehalten.

Man darf wohl sagen, daß durch die genannten Arbeiten die alte Auffàssung von der sehr geringen Flüchtigkeit der Milchsäure mit Wasserdämpfen durchweg bestätigt, Partheil's gegenteilige Angabe mithin widerlegt worden ist. In dieser Ansehauung wird man sich kaum dureh die ganz unerklärlichen Mitteilungen E. Welde's ${ }^{7}$ ) irre machen lassen. Auch nach ihm soll zwar Milchsäure, wenn man sie aus ihren wässerigen Lösungen im Wasserdampfstrome im Vakuum (bei etwa 60 $0^{\circ}$ ) abdestilliert, praktisch unflüchtig sein, führt man den Versuch jedoch unter gewöhnlichem Druck aus, so soll sie binnen 2 Stunden vollständig übergehen. Das widerspricht so sehr allen sonstigen Erfahrungen, daß man an einen Irrtum glauben muß.

1) Ich kann nicht umhin, hier darauf hinzuweisen, das die Mitteilungen Partheil's eine Reihe innerer Widersprüche aufweisen. So will er (S. 1056 seiner Arbeit) $500 \mathrm{ccm}$ Milchsäurelösung derart im Wasserdampfstrome destilliert haben, daß die Flüssigkeit auf etwa die Hälfte ihres Volumens konzentriert wurde, während $200 \mathrm{ccm}$ Destillat gesammelt wurden. Die Menge des Destillats hätte dann aber doch viel gröfer sein müssen als $200 \mathrm{ccm}$. Auf S. 1059 teilt er tinen Versuch mit, bei dem die quantitative Trennung von Essigsäure und Milchsäure mit sehr guten Ergebnissen durch Destillation gelungen war; das Destillat enthielt alle Essigsäure, der Destillationsrückstand alle Milehsäure. Sie war also in diesem Versuche praktisch unflüchtig geblieben. - Endlich hat er auf S. 1057 in den Destillaten von Wein, auch "stichigem“ Wein, nach Neutralisation mit Barytwasser lediglich ein Bariumsalz vom Bariumgehalt des Lactats erhalten. Das kann unmöglich richtig sein, denn es mulate neben Bariumlactat, und in wesentlich groberer Menge als dieses, Bariumacetat in dem neutralisierten Destillat vorhanden sein. Der Bariumgehalt des Salzes mukite also zwischen dem des Lactats und Acetats in der Mitte liegen und konnte nicht demjenigen des reinen Lactats entsprechen.

2) Diese Zeitschrift 1902, 5, 1062

3) Diese Zeitschrift 1903, 6, 729.

) Chem. Ztg. 1905, 29, 363 .

5) Journ. Americ. Chem. Soc. 1913, 35, 919.

*) Journ. Americ. Chem. Soc. 1913, 35, 91.

7) Biochem. Zeitschrift 1910, 28, 508 u. 512 . 
Auch meine jetzt angestellten neuen Versuche ergaben - gleich den schon vor Jahren unternommenen und damals nicht veröffentlichten - für die Flüchtigkeit der Milchsäure dieselben Beträge, wie sie Mayrhofer, Kunz, Utz, sowie Hart und Willaman gefunden hatten. $50 \mathrm{ccm}$ wässerige Milchsäurelösung - deren Gehalt an freier Milchsäure $49,29 \mathrm{ccm}$, an "gebundener" (d. h. nur nach Verseifung titrierbarer) Milchsäure $12,86 \mathrm{ccm}$, zusammen also $62,15 \mathrm{ccm} \% / 10 \mathrm{~N}$.-Lauge entsprach wurden nach Zusatz von $3 \mathrm{cem}$ verdünnter Schwefelsäure (vom spez. Gew. 1,15) in der Art destilliert, die unten im Gang der Analyse beschrieben ist. Die vereinigten Destillate bedurften bei der direkten Titrierung gegen Phenolphtbalein im Mittel zweier sehr gut übereinstimmender Versuche $0,87 \mathrm{ccm}$, und sodann zur Verseifung weiterer $1,14 \mathrm{~cm} 1 / 10 \mathrm{~N}$.-Lauge, zusammen $=2,01 \mathrm{ccm}$, also $3,2 \%$ der angewandten Menge. Anders waren jedoch die Ergebnisse, als Mischungen aller hier in Betracht gezogenen Säuren, d. h. Milchsäure in Gesellschaft von Ameisensäure, Essigsäure und Lävulinsäure, aus wässeriger Lösung in der eben bezeichneten Weise destilliert wurden. Ich gebe zunächst einen Auszug aus den Versuchsprotokollen; die Menge der angewandten und der im Destillat gefundenen Säuren ist durch die äquivalente Menge $1 / 10$ N.-Lauge ausgedrückt.

\begin{tabular}{l} 
Angewandt \\
\hline
\end{tabular}

Im Destillationsrückstand fand sich, bei seiner Analysierung nach den im vorhergehenden Teil dieser Arbeit niedergelegten Grundsätzen (ausführliche Arbeitsvorschrift folgt unten), bei beiden Versuchen merklich weniger Milchsäure als angewendet war; es mußten also nicht unwesentliche Anteile in das Destillat mit übergegangen sein. Sie ließen sich in diesem tatsächlich dadurch nachweisen, daß das Verbältnis des Chromatverbrauches beim Oxydationsversuch (abzüglich des Betrages für Ameisensäure) zur dabei neu gebildeten Essigsäure merklich kleiner war als 14; es betrug beim ersten Versuch nur 5,1, beim zweiten 6,2. Aus diesen Daten berechnete ich nach den von mir aufgestellten Formeln die Milchsäurewerte im Destillat, die in die letzte Tabelle eingeschrieben sind. Addiert man sie zu den im Rückstand gefundenen, so entspricht die Summe noch ausreichend der angewandten Menge Gesamt-Milchsäure. 
Zu dieser, nach den sonstigen Erfahrungen überraschenden, merklicheren Flüchtigkeit der Milchsäure gesellt sich aber noch ein weiteres: Die Flüchtigkeit der Milchsäure kommt in der Gesamtacidität des Destillates nicht zum Ausdruck. Diese Acidität gleicht nämlich praktisch nur der Summe der angewandten Essigsäure und der im Destillat nach der Mereurichloridmethode ermittelten Ameisensäure. Im ersten Versuche ist die Acidität $32,68 \mathrm{ccm} 1 / 10$ N.-Lauge gegenüber der Summe $31,12 \mathrm{ccm}$, im zweiten Versuch sind die entsprechenden Werte 42,33 bezw. $41,65 \mathrm{ccm}$. Auch nach erfolgter Verseifung ist, wie der zweite Versuch lehrt, die übergegangene Milchsäure noch nicht in ihrem vollen Betrage acidimetrisch nachzuweisen.

\section{Im Anschlusse hieran mögen aus dem Nachlasse Grïnhut's auch die von ihm mit dem Datum des 15. Mai 1919 versehenen Aufzeichnungen iiber Versuche fï den vorstehenden Vortrag zum Abdrucke gelangen.}

\section{Versuche über die quantitative Bestimmung ron Ameisensüure und Lïvulinsäure.}

I. Flüchtigkeit der Lävulinsäure mit Wasserdämpfen.

$\mathrm{Zu}$ den Versuchen diente eipe mit Einwage von 1,2144 $\mathrm{g}$ Lävulinsäure $\mathrm{Kahlbaum}$. auf $500 \mathrm{ccm}$ Wasser bereitete Lösung. $50 \mathrm{ccm}$ dieser Lösung brauchten a) $9,55-$ b) 9,55 im Mittel 9,55 ccm N.-Kalilange (Endanzeiger Phenolphthalein). Das entspricht 1,1084. g Lävulinsäure (=91\% der Einwage). Die eingewogene Säure war ziemlich stark zerflossen, daher der Minderbefund.

$50 \mathrm{ccm}$ dieser Lösung ( $=0,1108 \mathrm{~g}$ Lävulinsäure) wurden mit $5 \mathrm{ccm}$ verdünnter Schwefelsäure (d. 1,15) und $220 \mathrm{ccm}$ ausgekochtem Wasser versetzt und bis auf einen Rest von $20 \mathrm{ccm}$ abdestilliert, dann wurden $220 \mathrm{ccm}$ ausgekochtes Wasser zugegeben und abermals bis auf $20 \mathrm{ccm}$ abdestilliert. Dasselbe wurde ein drittes and viertes Mal nach jedesmaliger $\mathrm{Zu}$ gabe von wiederum $220 \mathrm{ecm}$ Wasser wiederholt. Die vier Destillate wurden einzeln titriert (Phenolphthalein als Endanzeiger); dabei orgab sich

\begin{tabular}{|c|c|c|c|c|c|c|c|}
\hline $0,0 \pm$ & $\mathrm{ccm}$ & ${ }^{1} / 10$ & N.-Kalilaug & $\theta=7,4$ & $\mathrm{mg}$ & Lävulinsäure & 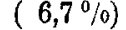 \\
\hline 2. 0,78 & \# & $\pi$ & $\pi$ & $=9,1$ & $\pi$ & $n$ & $8,2 \%$ \\
\hline 3. 0,93 & " & $n$ & , & $=10,8$ & $"$ & $"$ & $9,7 \%$ \\
\hline 4. 0,64 & " & & $\pi$ & $=7,4$ & $n$ & * & $6,7 \%)$ \\
\hline
\end{tabular}

II. Oxydation der Lävulinsäure mittels Chromsäure.

1. $50 \mathrm{ccm}$ Lävulinsäurelösung (enthaltend $0,1108 \mathrm{~g}$ ) wurden mit $4 \mathrm{~g}$ Chromsäure und $10 \mathrm{ccm}$ verdünnter Schwefelsänre (d. 1,15$)$ \& Stunden am Rückflußkühler erhitzt. Dann wurde der Kolben (in der Art wie bei Stillwell's Verfahren zur Bestimmung der Essigsäure) mit doppelt durchbohrtem Stopfen verschlossen; durch die eine Bohrung führte das Zuflakrohr einer Mariotte'schen Flasche, durch die andere war ein Reitmair'scher Destillieranfsatz gesteckt, an dem ein schräg abwärts geneigter Liebig'scher Kuhler angeschlossen war, Es wurde zunäehst bis auf $40 \mathrm{ccm}$ abdestilliert und dann, unter ständigem Zulauf von so viel Wasser aus der Mariotte'sehen Flasche, dabis die Raummenge im Kolben konstant $40 \mathrm{ccm}$ blieb, $1^{1 / 4}$ Stande lang destilliert. Das Destillat brauchte $10,04 \mathrm{ccm} 1 / 10 \mathrm{~N}$. Kalilauge, entsprechend $0,1165 \mathrm{~g}$ Lävulinsäure (-105,1\% der Einwage). - Der Kindampfungsrichastand des austitrierten Destillates wog (bei $100^{\circ}$ getrocknet) $0,1022 \mathrm{~g}$; ihm entsprach also das Äquivalentgewicht 102,2:1,004 $=101,8$ (Kaliumacetat $=98,1$ ). Dieser Ruckstand gab mit Schwefelsäure und Alkahol gekoeht Essigestergeruch.

2. Wioderholung desselben Versuches mit $75 \mathrm{ccm}$ Lävulinsäurelösung (enthaltend $0.1662 \mathrm{~g}$ ), $4 \mathrm{~g}$ Chromsäure und $10 \mathrm{ccm}$ verdünnter Schwefelsäure (d. 1,15). Das Destillat betrug $365 \mathrm{ccm}$; es verbrauchte (gegen Phenolphthalein) $15,10 \mathrm{ccm} 1 / 10 \mathrm{~N}$. Kalilauge $=0,1753 \mathrm{~g}$ Lä vulinsäure $(=105,5 \%)$.

1 Molekel Lãvulinsäure liefert also bei der Oxydation glatt 1 Molekel Essigsäure. Die geringe Erhöhung des Ergebnisses $(5 \%$; $)$ rührt wohl davon her, daß das bei der Oxydation nebenher entstandene Kohlendioyd am Rückfluß̉kühler nicht völlig entwich.

Un zu sehen, ob etwa neben Essigsäure unter den Oxydationsprodukten der Lävulinsäure sich Malonsäure oder Oxalsäure befand, wurde der Destillationsrückstand von Versuch 2 am Apparat von der Heide's drei Stunden lang mit Äther perforiert. Dabei wurde in das 
Kölbehen $10 \mathrm{ccm}$ N.Kalilauge gebracht. Das erhaltene Perforat wurde mit Kalilauge und Wasser ausgeschüttelt, die Lösung neutralisiert und mit Calciumehlorid versetzt. Es entstand $k e$ in Niederschlag.

III. Trennung von Ameisensäure und Lä

1. $20 \mathrm{~cm}$ Ameisensäurelösung (enthaltend $93,6 \mathrm{mg}$ ), $50 \mathrm{ccm}$ Lävulinsäurelösung (enthaltend $0,1108 \mathrm{~g}$ ) und $5 \mathrm{ccm}$ verdünnte Schwefelsäure (d. 1,15$)$ warden in von der Heide's Apparat drei Stunden mit Äther perforiert. Im Kölbehen befanden sich $10 \mathrm{ccm} 1 / 10 \mathrm{~N}$.Kalilauge: Die Ätherlösung warde mit der $1 / 10 \mathrm{~N}$.-Kalilange und danach mit Wasser ansgeschüttelt, die abgetrennten alkalisehen Lösungen samt den Waschwässern auf $100 \mathrm{ccm}$ gebracht. $40 \mathrm{ccm}$ dieser Lösung mit $4 \mathrm{~g}$ Chromsäure und $20 \mathrm{~cm}$ verdünnter Schwefelsäure $(d .1,15)$ wie zưor oxydiert und destilliert. Das Destillat brauchte für

$$
\text { die 1. Fraktion } 4,58 \mathrm{~cm} 1 / 10 \text { N.-Kalilauge }
$$

eine 2. kleinere Fraktion (etwa $75 \mathrm{ccm}$ ) 0,78 eine 3

$$
\begin{aligned}
& 0,10 " \# \text { " } \\
& 5,46 \mathrm{ccm}^{1 / 10} \text { N.-Kalilauge }
\end{aligned}
$$

Das entspricht $0,1584 \mathrm{~g}$ Lävulinsäure, also viel zu viel. Es war aber etwas chromsäure- und schwefelsäurehaltige Flüssigkeit infolge starken Stossens mit übergerissen worden. Deshalb wurde das neutralisierte Destillat nach dem Ansäuren mit Schwefelsäure im Dampfstrome noch e inmal destilliert, wobei das destillierte Wasser im Dampfentwickler mit Kalilauge versetzt worden war. Lennoch gaben zwei aufgefangene Fraktionen (die erste von etwa 300, die zweite von etwa $100 \mathrm{ccm}$ ) beim Titrieren

$$
\begin{aligned}
& \text { 1. Fraktion } 5,65 \mathrm{ccm} 1 / 10 \mathrm{~N} \text {.-Kalilauge } \\
& \text { 2. } \quad 0,97 \\
& \frac{6,62 \mathrm{ccm}^{n}}{1 / 10} \text { N.-Kalilauge }
\end{aligned}
$$

Das entspricht $0,1921 \mathrm{~g}$ Lävalinsäure, also noch mehr als zuvor; es musste also trotz des Laugenzusatzes Kohlendioxyd mit dem Dampfstrom angekommen sein. Dafür sprach bereits die ganze Art des Phenolphthalein-Umschlages (der anfangs immer wieder verschwand), das bewiesen dann die weiter unten folgenden Versuche.

2. $20 \mathrm{ccm}$ Ameisensäurelösung $(93,6 \mathrm{mg})$ und $50 \mathrm{ccm}$ Lävulinsäurelösung (110,8 $\mathrm{mg})$ und $5 \mathrm{ccm}$ verdünnte Schwefelsäure (d. 1,15) wurden wie zuvor drei Stunden perforiert. Im Kölbchen waren $10 \mathrm{ccm} 1 / 10 \mathrm{~N}$.-Kalilauge. Die Ausschüttelung wie zuvor gemacht und auf $100 \mathrm{ccm}$ gebracht.

a) Lävulinsäurebestimmung. $40 \mathrm{ccm}+4 \mathrm{~g}$ Chromsäure $+20 \mathrm{ccm}$ verdünnte Schwefelsäure am Rückfiufkühler zwei Stnnden gekocht. Dann nach Stillwell die Essigsäure abdestilliert. Verbrauch: $4,97 \mathrm{ccm}^{1 / 10} \mathrm{~N}$.-Kalilauge, entsprechend $0,1442 \mathrm{~g}$ Lävulinsäure. Viel zu viel; vielleicht übergespritzt wegen starken Stoßens. Der Kolben war sehr kurzhalsig.

b) Ameisensäurebestimmung. $40 \mathrm{ccm}$ mit ameisensäurefreier Essigsäure neutralisiert, auf etwa $100 \mathrm{cem}$ gebracht, mit $4 \mathrm{~g}$ Natriumacetat und $2 \mathrm{~g}$ Mercurichlorid eine Stunde am Rükflufkühler gekocht. Nach dem Erkalten mit $5 \mathrm{ccm}$ Salzsäure $(1,12)$ versetzt, über Goochtiegel filtriert, mit kaltem Wasser ausgewaschen, bei $100^{\circ}$ getrocknet und gewogen. Erhalten $0,4458 \mathrm{~g}$ Mercurichlorid $=108,6 \mathrm{mg}$ Àmeisensäure (in der ganzen Menge). Nochmals mit einer Mischung vou $100 \mathrm{ccm}$ kaltem $W$ asser und $10 \mathrm{~cm}$ Salzsätre (d. 1,12), dann mit Wasser allein ausgewasehen. Im Filtrat war mit Ammoniak und Ammoniumsulfid Mercuriion nachzoweisen. Der Niederschlag wog jetzt $0,3776 \mathrm{~g}$, entsprechend $92,0 \mathrm{mg}$ Ameisensäure. Diese Behandlung wurde wiederholt; das Filtrat war jetzt quecksilberfrei, der Niederschlag wog $0,3764 \mathrm{~g}$, entsprechend $91,8 \mathrm{mg}$ Ameisensäure.

3. $50 \mathrm{cem}$ einer neuen Lävulinsäurelosung (enthaltend $0,1827 \mathrm{~g}$ ) und $25 \mathrm{ccm}$ Ameisensäurelösung $(117,0 \mathrm{mg})$ sowie $5 \mathrm{ccm}$ verdünnte Schwefelsäure (d. 1,15) wurden in derselben Weise analysiert. Für die Lävulinsäurebestimmung (an 0,4 der Einwage) wurden $9,75 \mathrm{ccm}$ $1 / 10$ N.-Kalilauge verbraucht, entsprechend $0,2829 \mathrm{~g}$ Lävulinsäure für die ganze Menge. Anch hier war aber durch Stoßen Schwefelsäure und Chromsäure mit übergerissen. - Bei der Ameisensäurebestimmung wurden diesmal vor dem Filtrieren $10 \mathrm{ccm}$ Salzsäure (d. 1,12) zugesetzt; gewogen wurden dann 0,4606 $\mathrm{g}$ Mereurochlorid, entsprechend 112,2 mg Ameisensäure. Bei noehmaligem Auswaschen mit $100 \mathrm{ccm}$ Wasser $+10 \mathrm{cem}$ Salzsäure (d. 1,12) war das Filtrat quecksilberfrei, der Niederschlag wog nunmehr $0,4592 \mathrm{~g}$; entsprechend $111,9 \mathrm{mg}$ Ameisensäure.

IV. Bei dieser Versuchsreihe wurde beim Perforieren, statt mit Schwefelsäure, mit $5 \mathrm{ccm} 25 \%$-iger Phnsphorsäure angesäuert. Bei Suppenwürzen usw. wäre sonst zu befürchten, daf Chlorion in das Perforat übergeht und dann beim Abdestillieren der Eissigsäure aus der schwefelsauren Flüssigkeit Salzsäure mit übergehen könnte.

1. Vorversuch. $5 \mathrm{~g}$ Natriumehlorid in Wasser gelöst, mit $5 \mathrm{ccm} 25 \%$-iger Phosphorsäurelösung versetzt, wurden in gewohnter Weise mit Ather perforiert. Das Perforat erwies sich bei der Prüfung mit Silbernitrat als frei von Chlorion.

2. $25 \mathrm{ccm}$ Ameisensäurelösung (116,3 mg) und $50 \mathrm{ccm}$ Lävulinsäurelösung (182,7 mg) mit $5 \mathrm{ccm} 25 \%$-iger Phosphorsäure wie immer parforiert. Der banutzte Äther war durch 
Schatteln mit Lauge von Säure befreit. - Bei der Lävulinsäurebestimmung wurde (unter Einhaltung einer Raummenge von $40 \mathrm{ccm}$ ) aus dem $\mathrm{kur}$ zhalsigen Kolben im Wasserdampfstrom destilliert; der Wasserdampf wurde aus mit Kallauge alkalisch gemachtem Wasser entwickelt. Die gemachten 4 Fraktionen (aus $40 \mathrm{ccm}$ Lösung) brauchten

1. Fraktion $(420 \mathrm{ccm}) 8,43 \mathrm{~cm}{ }^{1} / 10 \mathrm{~N}$.-Kalilauge $=244,6 \mathrm{mg} \mathrm{C}_{5} \mathrm{H}_{8} \mathrm{O}_{3}$

$$
\begin{aligned}
& \text { 2. , }(50,) 0,54,, \quad=15,7,
\end{aligned}
$$

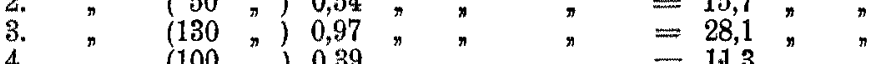

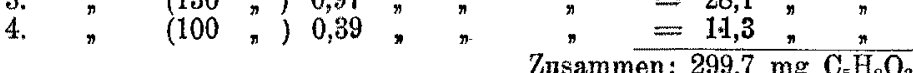

Anch hier war also wieder viel zu viel gefunden worden. Daß die Sehuld an mit übergegangenem Kohlendioxyd lag, wurde, wie folgt, bewiesen: Die austitrierte ers te Fraktion wurde zur Trockne gedampft und bei $100^{\circ}$ getrocknet. Der Rückstand wog $0,0824 \mathrm{~g}$; ihm entsprach also ein Aquivalentgewieht von $82,4: 0,843=97,7$. Kaliumacetat hat 98 , Kaliumhydrocarbonat 100. Der Rückstand brauste stark beim Übergieß̧en mit verdünnter Schwefelsẳre, enthielt also viel Carbonat; auferdem gab er auf weiteren Zusatz von Alkohol beim Kochen Essigestergeruch. - Die Ameisensäurebestimmung ergab nach dem ersten Waschen (wobei $10 \mathrm{~cm}$ Salzsäure $[1,12]$ zugesetzt waren) $0,4616 \mathrm{~g} \mathrm{Hg} \mathrm{Hl}_{2}=112,5 \mathrm{mg} \mathrm{CH}_{2} \mathrm{O}_{2}$, nach abermaligem Waschen mit salzsäurehaltigem Wasser (wobei aber das Filtrat von Anfang

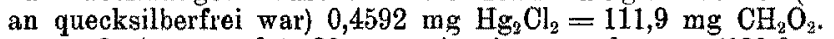

3 . Angewendet $30 \mathrm{ccm}$ Ameisensäurelösung $(139,6 \mathrm{mg}), 40 \mathrm{ccm}$ Lävulinsäurelösung $(146,1 \mathrm{mg}), 5 \mathrm{ccm} 25 \%$-ige Phosphorsäure; drei Stunden mit säurefreiem Ather perforiert. Bei der $L a ̈$ valinsäurebestimmung wurde diesmal aus langhalsigem, schräg gelegten Kjeldahlkolben mit Reitmai er'schem Aufsatz im Wasserdampfstrome destilliert (Dampf aus alkalisch gemachtem Wasser). Vier Fraktionen ergaben

$$
\begin{aligned}
& \text { 1. Fraktion (400 ccm) } 6,92 \mathrm{ccm}^{1} / 10 \mathrm{~N} \text {. Kalilauge }=200,8 \mathrm{mg} \mathrm{C}_{5} \mathrm{H}_{8} \mathrm{O}_{3}
\end{aligned}
$$

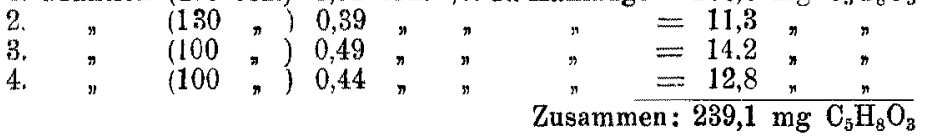

Auch hier war also sichtlich wieder Kohlensüure überdestilliert. Aus den drei letzten Fraktionen ergibt sich im Durchschnitt für je $100 \mathrm{ccm}$ Destillat eine scheinbare Lävulinsänremenge von 11,6 mg; bringt man demnaeh für die $400 \mathrm{cem}$ der ersten Fraktion eine Korrektur von $4 \times 11,6=46,4 \mathrm{mg}$ an, so ergibt sich als gefundene Lävulinsäure $200,8-46,4=154,4 \mathrm{mg}$. Das stimmt ungefähr mit der angewandten Menge; aber derartige Korrekturen sind natürlich unzulässig. - Bei der Ameisensäurebestimmung wurde diesmal beim ersten Waschen (Zusatz von $10 \mathrm{ccm}$ Salzsäare 1,12 ) $0,5882 \mathrm{~g} \mathrm{Hg}_{2} \mathrm{Cl}_{2}=143,2 \mathrm{mg}$, beim zweiten Waschen $0,5686 \mathrm{mg} \mathrm{HgCl} 2=138,5 \mathrm{mg}$ erhalten. Das Filtrat vom zweiten Waschen enthielt diesmal noch eine Spur Quecksilber.

V. Nachweis des Kohlendioxydfehlers.

Um darzutan, woher das Kohlendioxyd in den Destillaten bei der Lävulinsäurebestimmung stammt, wurden folgende Versuche angestellt:

1. Zunächst wurden in den beim letzten Versuch benutzten Apparat (langhalsiger Kolben) $40 \mathrm{ccm}$ destilliertes Wasser gebracht und im Wasserdampfstrome destilliert. Der Wasserdampf wurde aus mit Lauge alkalisch gemachtem Wasser entwickelt; zwei aufgefangene Fraktionen brauchten beim Titrieren

$$
\begin{array}{llll}
\text { 1. Fraktion }(500 \mathrm{ccm}) & 0,49 \mathrm{ccm}{ }^{1 / 10} \mathrm{~N} \text {.-Kalilauge } \\
2 . & (80 \mathrm{n}) & 0,05 \mathrm{~N}^{n}
\end{array}
$$

Der Phenolphthaleinumschlag war der für Kohlendioxydlösungen typische, zunächst immer wieder verschwindend. - Es war also, offenbar infolge Hydrolyse (vergl. die Arbeiten von Küster, Thiele u. a.) auch aüs dem alkalischen Wasser beim Kochen Kohlendioxyd entbunden worden.

2. Derselbe Versuch; nur war der Kolben von vornherein mit $40 \mathrm{ccm}$ Wasser, $4 \mathrm{~g}$ Chromsäure und $20 \mathrm{~cm}$ verdünnter Schwefelsäure $(1,15)$ beschickt. Das Volumen im Kolben wurde während der Destillation tunlicbst auf $40 \mathrm{ccm}$ erhalten. Zwei Fraktionen brauchten beim Titrieren:

$$
\text { 1. Fraktion }(380 \mathrm{~cm}) 1,07 \mathrm{ccm} 1 / 10 \mathrm{~N} \text {. Kalilauge }
$$

Auch hier war der Phenolphthaleinumschlag der für Kohlensäure typische. Es war mehr $\mathrm{CO}_{2}$ übergegangen wie im vorigen Versuch. Vielleicht war durch Verspritzen der infolge des sie durchströmenden Wasserdampfes stark aufschäumenden Flüssigkeit Chromsäure an den Stopfen gelangt und hatte durch Oxydation desselben Kohlendioxyd gebildet. Ein Überreiken von Schwefelsäure und Chromsäure lag nicht vor, denn das austitrierte und 
wieder angesäuerte Destillat blieb auf Zusatz von Bariumchlorid auch bei stundenlangem Stehen klar.

Nach dem Ergebnis dieser Versuche war also die Destillation im Wasserdampfstrome schon wegen der mit ihr verbundenen erhöhten Gefahr des Stopfenangriffes zn verlassen. Ich kehrte also zur Destillation nach Stillwell zuräck und legte in der Folge besonderes Gewicht auf die Verwendung praktisch kohlendioxydfreien Wassers.

VI. Neue Versuchsreihe.

Bei dieser wurde stets nach Stillwell unter tunlichster Einhaltung des Volumens der Flüssigkeit im Kolben von etwa $40 \mathrm{ccm}$ destilliert. Das Nacblaufwasser in der Mariotte'schen Flasche war gut ausgekocht und unter Absperrung durch ein Natronkalkrohr erkalten gelassen. Daun wurde es unter Natronkalkschutz in die Mario t te'sche Flasche übergehebert, die zuvor mit kohlendioxydfreier Lnft (durch Wasserverdrängung) gefüllt war. Das Eintrittsrohr für die Luftblasen in die Mario t te'sche Flasche war ebenfalls durch ein Natronkalkrohr gesrhützt. Der Destillationskalben wurde schräg, unter $45^{\circ}$ ansteigend, gelegt und mit $R$ eitm a ir'schem Aufsatz versehen. Es war ein birnförmiger Kjeldahlkolben von etwa 500 ccm Fassungsraum bis zum Halsansatz und $30 \mathrm{~cm}$ Gesamtlänge, davon $18 \mathrm{~cm}$ Halslänge. Der Kühler stieg schräg nach unten ab.

1. Angewendet $50 \mathrm{ccm}$ einer neuen Lävulinsäurelösung $(242,8 \mathrm{mg}), 25 \mathrm{ccm}$ Ameisensäurelösung $(116,3 \mathrm{mg}), 5 \mathrm{ccm} 25 \%$ ige Phosphorsäure. - Perforation wie sonst. Bei der Lävulinsäurebestimmung waren drei Fraktionen erforderlich, ehe alle Essigsäure übergegangen war. Die Titrierung derselben ergab:

$$
\begin{aligned}
& \text { 1. Fraktion }(360 \mathrm{ccm}) 7,85 \mathrm{ccm} 1 / 10 \text { N.-Kalilauge } \\
& \text { 2. (100) } 0,24
\end{aligned}
$$

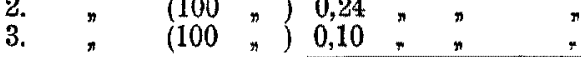

$$
\begin{aligned}
& \text { Zusammen: } 8,19 \mathrm{ccm} 1 / 10 \mathrm{~N} \text {-Kalilauge }=237,6 \mathrm{mg} \mathrm{C} \mathrm{H}_{8} \mathrm{O}_{3}
\end{aligned}
$$

Der Phenolphthaleinumsehlag war bei allen drei Fraktionen scharf und beständig. - Die A meisensäurebestimmung, bei welcher mit dem salzsauren Wasser gleich auf Queck. silberreaktion ausgewaschen warde, gab $0,4546 \mathrm{~g} \mathrm{HgCl}_{2}=111,8 \mathrm{mg}$.

2. Angewendet $60 \mathrm{ccm}$ Lävulinsäurelösung $(291,6 \mathrm{mg}), 20 \mathrm{ccm}$ Ameisensäurelösung $(93,0 \mathrm{mg}), 5$ ccm $25 \%$ ige Phosphorsäure. Ausführung wio beim vorigen Versuch. - Die L ä vulinsäurebestimmung ergab

$$
\begin{aligned}
& \text { 1. Fraktion }(280 \mathrm{ccm}) 9,50 \mathrm{ccm}^{1 / 10} \mathrm{~N} \text {.-Kalilauge }
\end{aligned}
$$

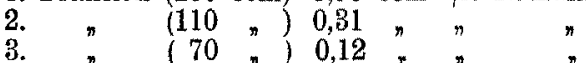

$$
\begin{aligned}
& \text { Zusammen: } 9,93 \mathrm{ccm} 1 / 10 \text { N.-Kalilauge }=288,1 \mathrm{mg} \mathrm{C}_{3} \mathrm{H}_{8} \mathrm{O}_{3}
\end{aligned}
$$

Die Ameisensäurebestimmung (A uswaschung wie beim vorigen Versuch) ergab $0,3660 \mathrm{~g}$ $\mathrm{Hg}_{2} \mathrm{Cl}_{2}=89,1 \mathrm{mg} \mathrm{H} \mathrm{CO}_{2}$.

Vorsitzender: Ich danke Herrn Kollegen $G r u ̈ n b u t$ für seine Mitteilungen, die allgemeines Interesse gerade deswegen gefunden haben, weil es sich darum handelt, einen neuen Stoff quantitativ in den Nahrungsmitteln bestimmen zu helfen.

\section{Diskussion.}

Dr. Witte: Mir hat gestern ein Herr mitgeteilt, ex hätte bei Kunsthonig $5 \%$ festgestellt, von denen er nicht wübte, was es wäre.

Dr. Sprinkmeyer-Stettin: Bei der Untersuchung von Kunsthonig sind 3 bis $5 \%$ übrig gebliehen, für die wir keine Erklärung haben.

Der Vorsitzende: Wir haben schon gestern in der Ausschubsitzung über diese Angelegenheit gesprochen. Es ist beschlossen worden, in der nächsten Hauptversammlung ein Referat über Kunsthonig vorzumerken. Es sind eine ganze Reihe von Fragen, die der Klärung bedürfen und in Verbindung mit den Industriellen gelöst werden müssen. Ich werde drei unserer Mitglieder in Vorschlag bringen, die gemeinsam mit zwei Vertretern der Industrie uns im nächsten Jahre über den Kunsthonig und seine Untersuchung Bericht erstatten sollen.

Geheimrat $J u c k e n a c k$ : Die Beobachtung ist nicht nur vereinzelt gemacht worden, sondern die hat schon zu grofien Erörterungen Veranlassung gegeben. Sie haben vor einigen Tagen die Mitteilung über ein Untersuchungsverfahren zugeschickt bekommen, wonach Kunsthonig untersucht werden soll. Es hat sich bei der Aufstellung von Grundsätzen heransgestellt, daf auch bei vorzüglich geleiteten Fabriken Differenzen vorkommen zwischen Gehalt an Trockenmasse und Invertzucker + Saccharose von durchschnittlich $6 \%$. Offensichtlich sind die 
schwankenden Mengen darauf zurüekzuführen, dac bei den verschiedenen Verfahren der Zusatz von starken anorganischen Săuren und der Einfluf dieser Sänren ein verschiedener ist, der Zucker auch nicht immer den Grad der Reinheit hat, and zum Teil wird diese anorganisehe Säure sehr heik wieder neutralisiert. Es spielen da eben verschiedene Momente mit, sodafs man zu dem Ergebnis kam, daß augenblicklich die Frage nicht spruchreif ist und man die ursprünglich beabsichtigte Fassung abgeändert hat und die Frage weiter geklärt werden soll.

Vorsitzender: Wird das Wort noch weiter gewünscht? Das schemt nicht der Fall zu sein. Danach können wir diesen Gegenstand verlassen und können übergehen zum folgenden Punkt unserer Tagesordnung: Empfiehlt es sich, auf Grund der in den öffentlichen Nahrungsmittelämtern bisher gesammelten Erfahrungen, die Ersatzlebensmittelgesetzgebung ab-oder weiter auszubauen?

Ich möchte Herrn Kollegen Juckenack bitten, uns das angesagte Referat nunmehr zu erstatten.

\title{
Empfiehlt es sich, auf Grund der in den Nahrungsmittel- untersuchungsämtern bisher gesammelten Erfahrnngen die Ersatzmittelgesetzgebung ab- oder weiter auszubanen?
}

\author{
Von \\ Geh. Reg-Rat Prof. Dr. Juckenack-Berlin.
}

Meine Herren! Wir stehen nunmehr vor der Ratifizierung des Friedensvertrages, und es interessiert die Behörden seit einiger Zeit lebhaft die Frage, inwieweit ein Abbau unserer Kriegsgesetzgebung in Frage kommt, oder inwieweit die in Betracht kommenden bestehenden Einrichtungen, Verordnungen usw. in die Übergangswirtschaft herüberzunehmen sind, und wieweit sie sich derart bewährt haben, daß sie überhaupt in die Friedensgesetzgebung übernommen werden können. Uns als Nahrungsmittelchemiker interessiert vor allem die Ersatzlebensmittelgesetzgebung. Daher ist auf die Tagesordnung die Frage gesetzt worden, ob sich ein Ausbau oder ein Abbau der Ersatzlebensmittelgesetzgebung empfiehlt, und zwar gerade auf Grund der Erfahrungen, die wir als Nabrungsmittelchemiker gemacht haben; denn die Ansichten der anderen Kreise sind darüber noch sehr geteilt.

Wenn man an die Prüfung dieser Frage herantritt, mul man sich vergegenwärtigen, warum diese Ersatzlebensmittelgesetzgebung während des Krieges geschaffen wurde. Der Zweck war zweifellos der, die groben Mißstände, die sich im Laufe des Krieges infolge des ständigen Rückganges der Lebensmittel eingeschlichen haben, zu beseitigen, und Sie werden sich aus der Zeit unmittelbar vor dem Erlab der Ersatzlebensmittelverordnung entsinnen, wie man überlegte, auf welche Weise man am besten diese Mißstände bekämpfen könne. Die Ansichten gingen zum Teil dahin, daß es zweckmäßig wäre, für die Fragen, die besonders kritisch waren, besondere Verordnungen zu erlassen; daher schufen wir die Verordnung gegen die irreführenden Bezeichnungen, dann die Verordnung vom 25. Oktober 1917 über die Regelung des Verkehrs mit Fleischbrühwürfeln und deren Ersatzmitteln, und man konnte die Ansicht vertreten, daß man da, wo Mißstände sich weiter entwickelten, z. B. im Verkehr mit den sog. Aromen, auch durch Sonderverordnungen die Auswüchse zu beseitigen 